\title{
Tissue heterogeneity in the mouse lung: effects of elastase treatment
}

\author{
Satoru Ito, ${ }^{1}$ Edward P. Ingenito, ${ }^{2}$ Stephen P. Arold, ${ }^{1}$ Harikrishnan Parameswaran, ${ }^{1}$ \\ Nora T. Tgavalekos, ${ }^{1}$ Kenneth R. Lutchen, ${ }^{1}$ and Béla Suki ${ }^{1}$ \\ ${ }^{1}$ Department of Biomedical Engineering, Boston University, and ${ }^{2}$ Division of Pulmonary and Critical \\ Care Medicine, Brigham and Women's Hospital, Harvard Medical School, Boston, Massachusetts 02115
}

Submitted 20 November 2003; accepted in final form 8 March 2004

\begin{abstract}
Ito, Satoru, Edward P. Ingenito, Stephen P. Arold, Harikrishnan Parameswaran, Nora T. Tgavalekos, Kenneth R. Lutchen, and Béla Suki. Tissue heterogeneity in the mouse lung: effects of elastase treatment. J Appl Physiol 97: 204-212, 2004. First published March 12, 2004; 10.1152/japplphysiol.01246.2003.-We developed a network model in an attempt to characterize heterogeneity of tissue elasticity of the lung. The model includes a parallel set of pathways, each consisting of an airway resistance, an airway inertance, and a tissue element connected in series. The airway resistance, airway inertance, and the hysteresivity of the tissue elements were the same in each pathway, whereas the tissue elastance $(\mathrm{H})$ followed a hyperbolic distribution between a minimum and maximum. To test the model, we measured the input impedance of the respiratory system of ventilated normal and emphysematous C57BL/6 mice in closed chest condition at four levels of positive end-expiratory pressures. Mild emphysema was developed by nebulized porcine pancreatic elastase (PPE) $(30 \mathrm{IU} /$ day $\times 6$ days). Respiratory mechanics were studied 3 wk following the initial treatment. The model significantly improved the fitting error compared with a single-compartment model. The PPE treatment was associated with an increase in mean alveolar diameter and a decrease in minimum, maximum, and mean $\mathrm{H}$. The coefficient of variation of $\mathrm{H}$ was significantly larger in emphysema (40\%) than that in control (32\%). These results indicate that PPE treatment resulted in increased time-constant inequalities associated with a wider distribution of $\mathrm{H}$. The heterogeneity of alveolar size (diameters and area) was also larger in emphysema, suggesting that the modelbased tissue elastance heterogeneity may reflect the underlying heterogeneity of the alveolar structure.
\end{abstract}

elastance; emphysema; modeling; distribution

DYNAMIC LUNG MECHANICAL FUNCTION can be conveniently assessed from input impedance measurement of the respiratory system or the lung over a range of frequencies by using the forced oscillation technique (28). Fitting a single-compartment model of the lung to impedance data acquired over an appropriate frequency range allows for partitioning lung mechanical properties into airway and tissue components (17). The approach of fitting a single-compartment model to the data to partition lung impedance to airway and tissue components has become popular and was applied to the normal lung (13, 16, $32,35)$ and a variety of conditions mimicking diseases, such as emphysema (6), acute lung injury (2), and asthma in which airways undergo constriction $(1,25,31)$. However, Bates et al. (5) and Lutchen et al. (24) found that, during constriction, considerable heterogeneity develops in the lung, and, as a consequence, the partitioning of lung resistance to airway and tissue components based on the single-compartment model can lead to an overestimation of tissue resistance. To take into

Address for reprint requests and other correspondence: B. Suki, Dept. of Biomedical Engineering, Boston Univ., 44 Cummington St., Boston, MA 02215 (E-mail: bsuki@bu.edu). account airway heterogeneities, Suki et al. (40) developed a distributed model of airway pathways with different airway resistances (Raw) but identical tissue elements. It was shown that this new model incorporating airway-related, time-constant inequalities could provide a significantly improved partitioning of airway and tissue properties from impedance data during heterogeneous constriction in dogs (40), as well as in normal rats (35).

Most studies have concentrated on airway heterogeneities. However, it is well known that, for some diseases (e.g., emphysema and acute lung injury), heterogeneities do exist at the level of the tissue $(3,18,34)$. At the level of isolated parenchymal tissue strips, several in vitro studies showed that changes in tissue structure and matrix composition can alter tissue mechanics, especially dynamic tissue elastance $(8,33$, $41,44)$. In the whole lung, such changes in parenchymal structure and composition should result in considerable heterogeneity of dynamic tissue properties. Indeed, the lung tissue becomes extremely heterogeneous in emphysema (34). The large heterogeneity of low-attenuation areas in computed tomography images of emphysematous patients (3) is likely to correspond to a wide distribution of regional tissue elastance in the lung. Additionally, in acute respiratory distress syndrome, the lung often has large areas of flooded alveoli (18), as well as patchy alveolar regions with surfactant dysfunction (15), both of which lead to increased regional lung elastance (12). Thus such variations in parenchymal structure and composition throughout the lung are likely to induce heterogeneity of tissue elastance and hence a wide distribution of time constants, which, in turn, should be reflected in changes in lung impedance.

The purpose of the present study was to compare the time-constant inequalities associated with a distribution of tissue elastance in the normal and emphysematous lung. To this end, we developed a new model in which the distribution of time constants in the lung is related to heterogeneity of regional tissue elastance. We derived equations for the input impedance of the model in terms of Raw and airway inertance (Iaw) and parameters characterizing the distribution of tissue elastance, which allows us to estimate tissue elastance heterogeneities from impedance data measured over a range of frequencies. To test the applicability of the model, we investigated the heterogeneity of dynamic tissue elastance obtained from respiratory input impedance of mice, with or without porcine pancreatic elastase (PPE) treatment, which is known to introduce a distribution of emphysematous lesions in the lung (23). Furthermore, in an attempt to relate the tissue elastance

The costs of publication of this article were defrayed in part by the payment of page charges. The article must therefore be hereby marked "advertisement" in accordance with 18 U.S.C. Section 1734 solely to indicate this fact. 
heterogeneity to morphological heterogeneity, we examined several morphological features of the alveolar structure at the microscopic level.

\section{Model Development}

Homogeneous model. Hantos et al. (17) introduced a linear tissue impedance $\left(\mathrm{Z}_{\mathrm{t}} \mathrm{i}\right)$ model called the constant-phase model. The $\mathrm{ZL}_{\mathrm{ti}}$ is calculated as

$$
\mathrm{Z}_{\mathrm{ti}}\left(\omega_{\mathrm{n}}\right)=(\mathrm{G}-j \mathrm{H}) / \omega_{\mathrm{n}}^{\alpha}
$$

with $\alpha=2 / \pi \arctan (\mathrm{H} / \mathrm{G})$ and $\omega_{\mathrm{n}}=\omega / \omega_{0}$. In Eq. $1, \omega_{\mathrm{n}}$ and $\omega$ are the normalized and absolute circular frequency, respectively, $\mathrm{G}$ and $\mathrm{H}$ are the coefficients of tissue damping and elastance, respectively, and $j$ is the imaginary unit. The exponent $\alpha$ describes the frequency dependence of tissue resistance $\left[\mathrm{Rti}=\mathrm{G} /\left(\omega_{\mathrm{n}}\right)^{\alpha}\right]$ and tissue elastance $\left[\mathrm{Eti}=\mathrm{H}\left(\omega_{\mathrm{n}}\right)^{1-\alpha}\right]$. The normalization factor $\omega_{0}=1 \mathrm{rad} / \mathrm{s}$ is introduced for the following reasons. Without the normalization, the unit of the parameters $\mathrm{G}$ and $\mathrm{H}$ is $\mathrm{kPa} / \mathrm{Hz}^{1-\alpha}$, which is cumbersome and changes from subject to subject as it includes $\alpha$. Our normalization, however, provides the same numerical value as without normalization; at the same time it also guarantees appropriate "elastance" unit for G and H. The lung or respiratory system impedance can be obtained by adding the impedance of the airway tree (Zaw) in series to the $\mathrm{ZL}_{\mathrm{t}}$, where $\mathrm{Zaw}$ is the series combination of an Raw and an Iaw.

$$
\mathrm{Zaw}=\mathrm{Raw}+j \omega \mathrm{Iaw}
$$

In this model, there are four parameters to estimate from the impedance spectra: Raw, Iaw, G, and H.

Heterogeneous elastance model. To account for the presence of lung tissue heterogeneities, we represent the airway tree by a set of parallel pathways, each composed of an Raw, an Iaw, and a tissue compartment (Fig. 1). We assume that the values of Raw and Iaw are the same in each pathway. We also assume that each tissue compartment can be described with the constant-phase impedance of $E q$. l, but each compartment has a different $\mathrm{H}$ value. The goal is to find a closed-form expression of the impedance of the network suitable for model fitting. It can be seen from $E q .1$ that, if $\mathrm{H}$ is distributed, then $\alpha$ will also be distributed, which does not allow for a simple solution of the network. To avoid this difficulty, we first reformulate Eq. 1

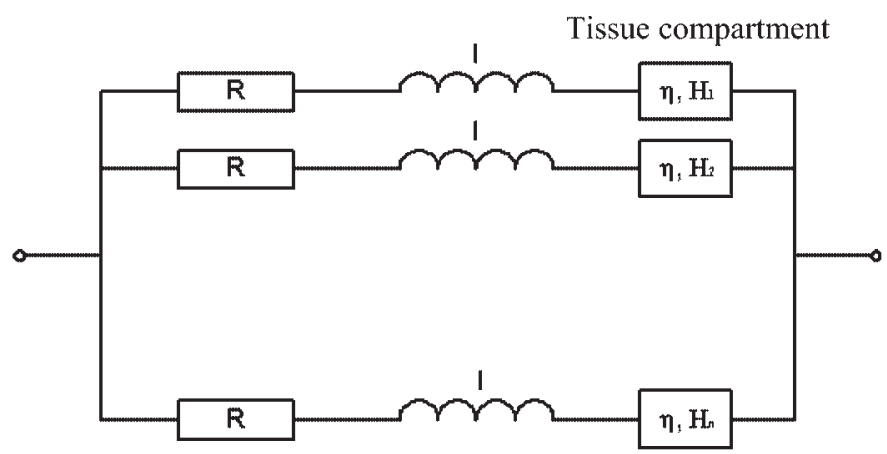

Fig. 1. Network model of the respiratory system, which is a parallel combination of pathways, each containing airway resistance (R; Raw), inertance (I), and a tissue compartment connected in series. The tissue compartments have the same hysteresivity $(\eta)$, but the tissue elastance $(\mathrm{H})$ is distributed between $\mathrm{H}_{1}$ and $\mathrm{H}_{n}$. in terms of the hysteresivity $(\eta)$, a material property of the tissue (11), defined as the ratio $\mathrm{G} / \mathrm{H}$ :

$$
\mathrm{ZL}_{\mathrm{ti}}\left(\omega_{\mathrm{n}}\right)=(\eta-j) \mathrm{H} / \omega_{\mathrm{n}}^{\alpha},
$$

with $\alpha=2 / \pi \arctan (1 / \eta)$. Thus, if we assume that each tissue compartment has the same $\eta$, $\alpha$ will not depend on the particular distribution of $\mathrm{H}$. To derive the input impedance of the model, we note the following. The network in Fig. 1 is similar to that published by Suki et al. (40) in which timeconstant heterogeneities were a result of the distribution of Raw. The difference between the present model and that of Suki et al. is that, in the latter, Raw was distributed, and G and $\mathrm{H}$ were the same in each compartment. Examining, however, the derivations in Ref. 40, we realized that the closed-form solution is completely symmetric in $\mathrm{Zaw}$ and $\mathrm{ZL}_{\mathrm{ti}}$. Therefore, instead of providing a full derivation, it suffices to interchange the roles of $\mathrm{Zaw}$ and $\mathrm{ZL}_{\mathrm{ti}}$ and Raw and $\mathrm{H}$. Accordingly, if we assume that the distribution function (p) of $\mathrm{H}$ is hyperbolic, $\mathrm{p}(\mathrm{H})=1 / \mathrm{H}$, between a minimum $\left(\mathrm{H}_{\min }\right)$ and maximum value of $\mathrm{H}\left(\mathrm{H}_{\max }\right)$, the input impedance $\mathrm{Z}$ of the network is obtained by symmetry arguments from Ref. 40 as

$$
\mathrm{Zin}=\frac{\mathrm{FZaw}}{\mathrm{F}+\ln \left(\frac{\mathrm{ZL}_{\mathrm{t} \text {,min }}+\mathrm{Zaw}}{\mathrm{ZL}_{\mathrm{t} \text {,max }}+\mathrm{Zaw}}\right)}
$$

where $\mathrm{F}$, minimum $\mathrm{ZL}_{\mathrm{ti}}\left(\mathrm{ZL}_{\mathrm{t} i \text { min }}\right)$, and maximum $\mathrm{ZL}_{\mathrm{ti}}\left(\mathrm{ZL}_{\mathrm{ti}, \max }\right)$ are given by $\mathrm{F}=\ln \left(\mathrm{H}_{\max } / \mathrm{H}_{\min }\right), \mathrm{ZL}_{\mathrm{ti}, \min }\left(\omega_{\mathrm{n}}\right)=(\eta-j) \mathrm{H}_{\min } /$ $\omega_{\mathrm{n}}^{\alpha}$, and $\mathrm{ZL}_{\mathrm{ti}, \max }\left(\omega_{\mathrm{n}}\right)=(\eta-j) \mathrm{H}_{\max } / \omega_{\mathrm{n}}^{\alpha}$, respectively.

By minimizing the root-mean-square difference between the model and the data (7), the five parameters (Raw, Iaw, $\eta, \mathrm{H}_{\min }$, and $\left.\mathrm{H}_{\max }\right)$ were determined. The mean $\mathrm{H}$ value $\left(\mathrm{H}_{\text {mean }}\right)$ was estimated as the first moment of the distribution function $\mathrm{p}(\mathrm{H})$; the mean $\mathrm{G}\left(\mathrm{G}_{\text {mean }}\right)$ was calculated as $\mathrm{G}_{\text {mean }}=\eta \mathrm{H}_{\text {mean }}$. The heterogeneity in dynamic tissue elastance was characterized by the coefficient of variation $(\mathrm{CV})$ of $\mathrm{H}$, defined as the ratio of the standard deviation (SD) of $\mathrm{p}(\mathrm{H})$ to $\mathrm{H}_{\text {mean }}$, both calculated from the estimates of $\mathrm{H}_{\min }$ and $\mathrm{H}_{\max }$ as

$$
\mathrm{H}_{\text {mean }}=\frac{\mathrm{H}_{\text {max }}-\mathrm{H}_{\text {min }}}{\mathrm{F}}
$$

and

$$
\text { SD of } \mathrm{p}(\mathrm{H})=\sqrt{\frac{\left(\mathrm{H}_{\max }^{2}-\mathrm{H}_{\min }^{2}\right)}{2 \mathrm{~F}}-\frac{\left(\mathrm{H}_{\max }-\mathrm{H}_{\min }\right)^{2}}{\mathrm{~F}^{2}}}
$$

Thus the $\mathrm{CV}$ of $\mathrm{H}$ is obtained by

$$
\mathrm{CV}=\sqrt{\frac{\mathrm{F}\left(\mathrm{H}_{\max }+\mathrm{H}_{\min }\right)}{2\left(\mathrm{H}_{\max }-\mathrm{H}_{\min }\right)}-1}
$$

Computational airway tree model. To determine whether the new model is able to extract meaningful distributions from experimental data, we tested the model on simulated impedance spectra with known distributions of $\mathrm{H}$. We first developed a stochastic tree model of the mouse airway structure using the design algorithm of Kitaoka and Suki (20). The algorithm is based on flow partitioning, whereby the flow $\mathrm{Q}$ in a parent segment is partitioned to $r \dot{\mathrm{Q}}$ and $(1-r) \mathrm{Q}$ in the two daughter segments, where $r \leq 0.5$ is the flow partitioning parameter. 
The value of $r$ can be taken from a distribution, and the partitioning is continued until the flow becomes less than a threshold flow, $\dot{\mathrm{Q}}_{\mathrm{c}}$. The asymmetry of the tree is governed by $r$, and the size of the tree is determined by $\dot{\mathrm{Q}}_{\mathrm{c}}$. We used $r=$ 0.35 and $\dot{Q}_{c}=0.0006$, which were calculated from the data of Gomes and Bates (14). The diameter relative to the trachea of each segment was then calculated as $d \sim \dot{\mathrm{Q}}^{m}$, where $m=2.8$ is the diameter exponent. The length of each segment was also a random variable and was taken to be, on average, three times the diameter of the segment. The generated tree had 3,071 branches, and the number of terminal branches was 1,536. Next, we added two different elastance distributions: a constant $\mathrm{H}$ of $35 \mathrm{cmH}_{2} \mathrm{O} / \mathrm{ml}$ and a hyperbolic $\mathrm{H}$ distribution between 10 and $85 \mathrm{cmH}_{2} \mathrm{O} / \mathrm{ml}$ with an average value of $35 \mathrm{cmH}_{2} \mathrm{O} / \mathrm{ml}$. The resistance, inertance, and airway wall properties of each segment were calculated, and the input impedance of the entire tree was obtained, both with rigid and floppy airway wall models, as described previously (42). The tissue $\eta$ was set to be 0.2 in each simulation. The impedance spectra were then fit with the model of Eq. 4, and the estimated parameters were compared with their true values.

\section{METHODS}

\section{Animal Preparation}

Two groups of male C57BL/6 mice (Charles River Laboratories, Boston, MA) were studied. All animal procedures were approved by the Animal Care and Use Committees of Boston University and Harvard Medical School. Emphysema was developed by administrating nebulized PPE (Sigma Chemical, St. Louis, MO) by using a modification of the tracheal instillation protocol by Lucey et al. (23). Mice were treated either with nebulized $30 \mathrm{IU}$ PPE $(n=6)$ or the same amount of saline (control, $n=6$ ) three times a week for 2 wk. An amount of $30 \mathrm{IU}$ of PPE was dissolved in $3 \mathrm{ml}$ of sterile saline and nebulized for $30 \mathrm{~min}$ by using a Tiger brand acorn nebulizer with a stream of air at $61 / \mathrm{min}$ with the animals placed in a small plexibox $(18 \times 30 \times 15 \mathrm{~cm})$. Three weeks following the initial treatment, the animals were deeply anesthetized by intraperitoneal injection of pentobarbital $(70 \mathrm{mg} / \mathrm{kg})$, tracheostomized, and cannulated in the supine position. The cannula was connected to a computer-controlled ventilator (Flexivent, SCIREQ, Montreal, Canada). Following the experiments, the animals were killed by administration of pentobarbital $(70 \mathrm{mg} / \mathrm{kg}$ ), and the lungs were removed for histopathological evaluation. There were no significant differences in body weight between the PPE-treated and the control groups $(25.4 \pm 1.0 \mathrm{vs}$. $24.8 \pm 0.9 \mathrm{~g})$.

\section{Protocol}

Mice were mechanically ventilated with room air by using a tidal volume (VT) of $8 \mathrm{ml} / \mathrm{kg}$ at a frequency of 240 breaths $/ \mathrm{min}$. After stabilization, respiratory mechanics were measured at four different positive end-expiratory pressure (PEEP) levels $\left(0,3,6\right.$, and $\left.9 \mathrm{cmH}_{2} \mathrm{O}\right)$ in the closed chest condition. Dynamic respiratory function was assessed by measuring impedance data during forced oscillatory maneuvers by using a computer-controlled ventilator system (Flexivent) applying the optimal ventilator waveform (OVW) technique (26). To standardize volume history, each measurement was preceded by two consecutive inflations of the lungs to total lung capacity, defined as a tracheal pressure of $25 \mathrm{cmH}_{2} \mathrm{O}$.

\section{Impedance Measurements}

Impedance data collection was made by interrupting mechanical ventilation for $6 \mathrm{~s}$ by using the OVW, which is a broadband waveform containing energy from 0.5 to $15 \mathrm{~Hz}$ (26). The frequencies in the
OVW are selected according to a nonsum nondifference (NSND) criterion, which eliminates harmonic distortion and minimizes cross talk among the frequencies that are present in the input flow waveform and hence provides smooth estimates of the input impedance of the system (39). The volumes delivered are similar to normal spontaneous $\mathrm{V}_{\mathrm{T}}$ values but in a closed-circuit, forced-oscillatory system. In our experiment, we matched the peak-to-peak OVW amplitude to the VT delivered by the mechanical ventilator. The ventilator displacement and cylinder pressure signals were low-pass filtered at $30 \mathrm{~Hz}$ and sampled at $256 \mathrm{~Hz}$. With the use of Fourier analysis, impedance spectra were calculated on overlapping blocks of pressure and flow data as the ratio of the cross-power spectrum of pressure and flow and the autopower spectrum of flow. The forced-oscillatory system was calibrated by measuring the input impedance of known analogs, including tubes and bottles with known impedances. The frequency response of the system was obtained, and the measured impedance spectra were off-line corrected for any phase difference between pressure and flow. Additionally, the flow-dependent impedance of the tracheal cannula was characterized separately and removed from the respiratory impedance of the mice.

\section{Histopathological Analysis}

Thin tissue slices were prepared by using a method that preserves their structural integrity (21). In both groups, the lungs were infused with $1 \%$ agarose solution at $55^{\circ} \mathrm{C}$ under constant positive pressure of $25 \mathrm{cmH}_{2} \mathrm{O}$, and the agarose was allowed to gel at room temperature ( $n=3$ in each group). The agarose-filled lungs were then sliced with a vibratome to generate slices of $\sim 5 \times 3 \times 0.5 \mathrm{~mm}$ in dimensions. Autofluorescent images of the alveolar structure were taken with a fluorescent microscope (Zeiss Axiovert 100TV), and features of the alveolar structure were determined as follows. First, ellipses were fit in each alveolus, and the diameter was computed as the mean of the major and minor axis of the ellipse. The area was calculated as the area of the ellipse. The alveolar wall thickness was measured in a semiautomated manner by manually selecting regions of the alveolar walls. Tissue fraction was calculated as the ratio of the alveolar wall areas in a region to the total area of the region. The mean and SD values of these parameters were then compared by using statistical tests.

\section{Statistical Analysis}

All data are expressed as means $\pm \mathrm{SD} ; n$ is the number of preparations used. Student's $t$-test, $F$-test, and repeated-measures two-way ANOVA were used to evaluate the significance of differences between means and variances, with $P<0.05$ as the level of significance (SigmaStat, SPSS).

\section{RESULTS}

\section{Application of the Model to Simulated Data}

Table 1 summarizes the respiratory mechanical parameters estimated from the simulated impedance data. The heterogeneous tissue elastance model fits the data well, with a small error for each case. The $\eta$ values were within $6 \%$ of the assumed value of 0.2 . The values of $H_{\text {mean }}$ were also very close to the value of $35 \mathrm{cmH}_{2} \mathrm{O} / \mathrm{ml}$ used in the constant $\mathrm{H}$ case. For the distributed $\mathrm{H}$ model with rigid walls, the $\mathrm{H}_{\text {mean }}$ was estimated to be $\sim 20 \%$ smaller than the mean of the distribution. This is due to the underestimation of the $85 \mathrm{cmH}_{2} \mathrm{O} / \mathrm{ml}$ used for the $\mathrm{H}_{\max }$ value in the simulation. Although $\mathrm{H}$ was distributed between $\sim 25$ and $40 \mathrm{cmH}_{2} \mathrm{O} / \mathrm{ml}$, even in the constant $\mathrm{H}$ case, the $\mathrm{CV}$ of $\mathrm{H}$ was considerably larger extracted from impedances corresponding to the distributed $\mathrm{H}$ case (30 and $51 \%$, respectively) than from that of the constant $\mathrm{H}$ case 
Table 1. Respiratory mechanical parameters estimated from simulated data

\begin{tabular}{lcccccc}
\hline \hline & Error & Hysteresivity & $\mathrm{H}_{\min }$ & $\mathrm{H}_{\max }$ & $\mathrm{H}_{\text {mean }}$ & $\mathrm{CV}$ \\
\hline Constant & & & & & & \\
$\quad$ FL & 0.004 & 0.189 & 24.7 & 44.1 & 33.5 & 16.7 \\
$\quad$ RIG & 0.022 & 0.209 & 27.5 & 41.1 & 33.9 & 11.5 \\
Hyperbolic & & & & & & \\
$\quad$ FL & 0.001 & 0.195 & 11.1 & 68.7 & 31.6 & 51.3 \\
RIG & 0.005 & 0.201 & 15.5 & 43.9 & 27.3 & 29.8 \\
\hline
\end{tabular}

Values of the errors between data and model fit (Error), tissue elastance $(\mathrm{H})$ parameters $\left(\mathrm{H}_{\min }\right.$, minimum $\mathrm{H} ; \mathrm{H}_{\max }$, maximum $\mathrm{H} ; \mathrm{H}_{\text {mean }}$, mean $\left.\mathrm{H}\right)$, and $\mathrm{CV}$ (coefficient of variation of $\mathrm{H}$ distribution) are expressed as $\mathrm{cmH}_{2} \mathrm{O} \cdot \mathrm{s}^{-1} \cdot \mathrm{ml}$, $\mathrm{cmH}_{2} \mathrm{O} / \mathrm{ml}$, and percent, respectively. Constant, a constant $\mathrm{H}$ distribution model; hyperbolic, a hyperbolic $\mathrm{H}$ distribution model; FL, a floppy airway wall model; RIG, a rigid airway wall model.

(12 and 17\%, respectively) with rigid and floppy airway walls. These findings indicate that our distributed $\mathrm{H}$ model is able to differentiate between small and large heterogeneity in $\mathrm{H}$, and hence it should be able to extract tissue heterogeneity from experimental data.

\section{Respiratory Impedance Data and Model Fits}

The heterogeneous elastance model fits the data well at all PEEP levels in both groups. The fitting errors of the distributed elastance model were compared with the errors of the homogeneous model introduced by Hantos et al. (17). The fitting errors corresponding to both models significantly depended on PEEP in both groups $(P<0.01)$. Generally, the difference between the fitting errors decreased with increasing PEEP. When all PEEP levels were considered, the difference between fitting errors in the control group nearly reached a statistically significant difference $(P=0.052)$. However, at PEEP levels of 0 and $3 \mathrm{cmH}_{2} \mathrm{O}$, the new model improved the errors compared with the homogeneous model $(P<0.05)$ (Fig. $2 A)$. In PPEtreated mice, the fitting errors of the heterogeneous elastance model were statistically significantly smaller than those of the homogeneous model at all PEEP levels $(P<0.001)$ (Fig. $2 B)$. Therefore, in the following, we only use the new model to characterize the dynamic respiratory mechanics of ventilated mice before and after PPE treatment. Figure 3 shows representative cases of the resistance and dynamic elastance calculated as the product of the imaginary part of the impedance and $-\omega$ and the fits of the model to the data in a control and a PPE-treated mouse at the PEEP level of $3 \mathrm{cmH}_{2} \mathrm{O}$. The difference in resistances was relatively small (Fig. $3 A$ ). However, the dynamic lung elastance of PPE-treated mice was lower by $\sim 25 \%$ compared with control mice and displayed a larger frequency dependence, suggesting the presence of increased time-constant heterogeneities compared with control (Fig. 3B).

\section{Tissue Elastance Distributions and}

Time-constant Heterogeneities

Figure 4 shows two examples of the hyperbolic distributions of tissue elastance between $\mathrm{H}_{\min }$ and $\mathrm{H}_{\max }$ in control and PPE-treated mice at PEEP levels of 0 and $6 \mathrm{cmH}_{2} \mathrm{O}$, respectively. PPE treatment resulted in a relatively large decrease (30-40\%) in $\mathrm{H}_{\min }$ at both PEEP levels. The $\mathrm{H}_{\max }$ also decreased in the treated animal at PEEP $=6 \mathrm{cmH}_{2} \mathrm{O}$. From these distributions, the average tissue elastance $\mathrm{H}_{\text {mean }}$ values were calculated by using Eq. 5. The parameters $\mathrm{H}_{\min }, \mathrm{H}_{\max }$, and $\mathrm{H}_{\text {mean }}$ were significantly PEEP dependent $(P<0.001$, Fig. 5). Using two-way repeated-measures ANOVA, there was no significant difference in $\mathrm{H}_{\max }$ between the control and the PPE-treated groups $(P=0.12$, Fig. $5 A)$. However, with increasing PEEP, the difference in $\mathrm{H}_{\max }$ in the two groups gradually increased, reaching statistically significant levels at 3 , 6, and $9 \mathrm{cmH}_{2} \mathrm{O}(P<0.01)$. Both $\mathrm{H}_{\text {min }}$ and $\mathrm{H}_{\text {mean }}$ in the PPE-treated mice were significantly lower compared with that in the control mice $(P<0.01$ and $P<0.001$, respectively $)$ (Fig. 5). Heterogeneity of tissue elastance can also be characterized by the $\mathrm{CV}$ ( $E q .7$ ) of the $\mathrm{H}$ distribution, which was significantly PEEP dependent in the PPE-treated $(P<0.001)$ but not in the control mice (Fig. 6). The CV in the PPE-treated mice was significantly larger than that in the control mice $(P<$ 0.05 ), and the difference (51 vs. $36 \%$ ) was the largest at PEEP of $0 \mathrm{cmH}_{2} \mathrm{O}$.

\section{Respiratory Mechanical Parameters}

Raw was significantly PEEP dependent $(P<0.001)$ and decreased when PEEP was increased in both groups (Fig. 7). The $\eta$ was significantly PEEP dependent in PPE-treated mice $(P<0.001)$ but not in control mice. The Raw was significantly lower $(P<0.01)$ and the $\eta$ was higher $(P<0.05)$ in the
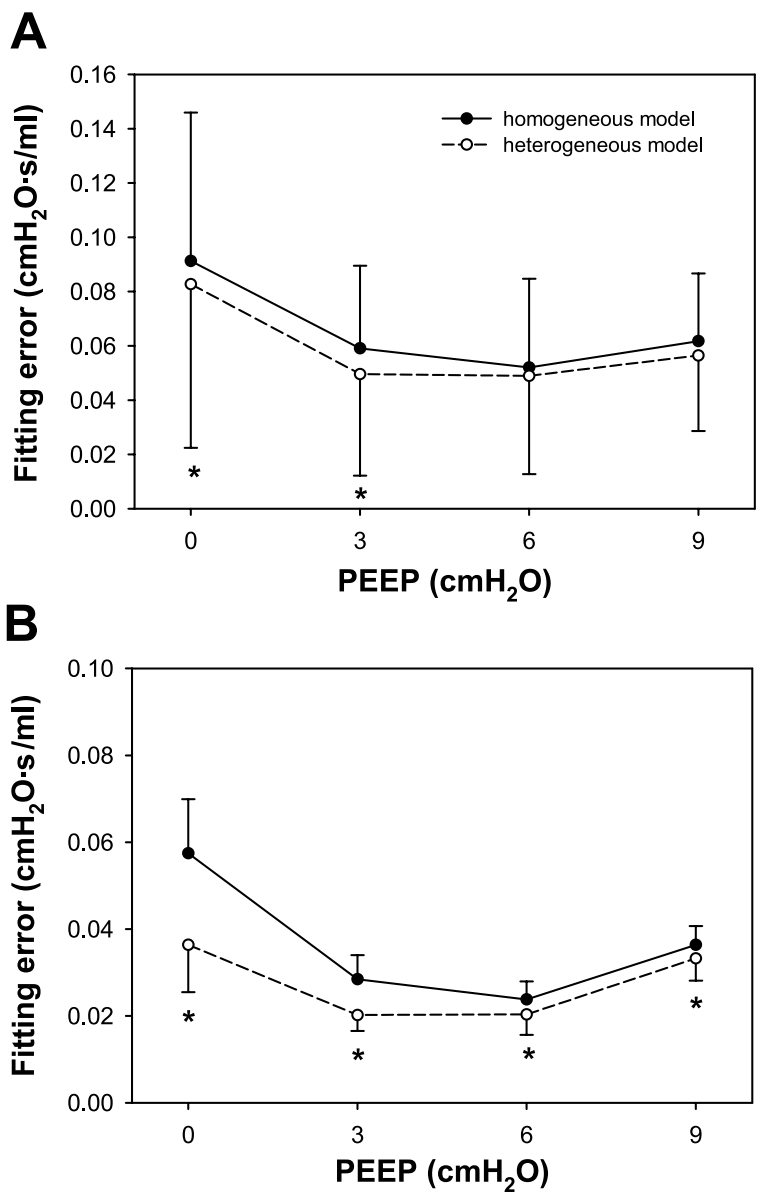

Fig. 2. Fitting errors corresponding to the homogeneous $(\bullet)$ and the heterogeneous $(O)$ models in control $(A)$ and porcine pancreatic elastase (PPE)-treated $(B)$ mice as a function of the positive end-expiratory pressure (PEEP). Values are means $\pm \mathrm{SD}$. $* P<0.05$. 


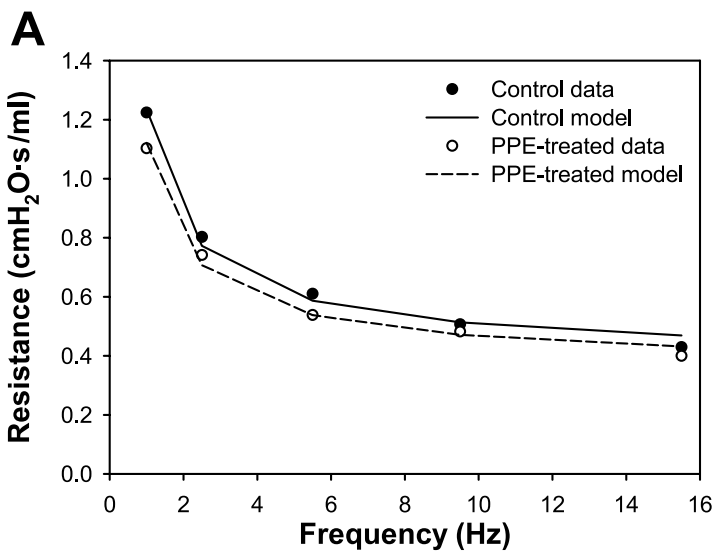

B

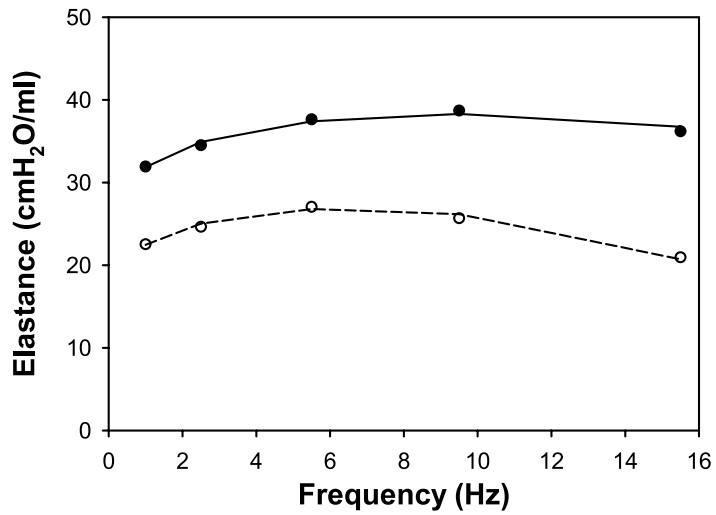

Fig. 3. Representative examples of respiratory system $\mathrm{R}(A)$ and $\mathrm{H}(B)$ calculated from the impedance data in control $(\bullet)$ and PPE-treated $(O)$ mice and fits of the model to the control (solid line) and PPE-treated (dashed line) data at PEEP of $3 \mathrm{cmH}_{2} \mathrm{O}$.

PPE-treated group than in control (Fig. 7, $A$ and $B$, respectively). There were no significant differences in $\mathrm{G}_{\text {mean }}$ calculated from $\eta$ and $\mathrm{H}_{\text {mean }}$ between the two groups.

\section{Alveolar Structure}

Figure 8 shows representative alveolar structures of a control and a PPE-treated lung under the fluorescent microscope $3 \mathrm{wk}$ following initial treatment. Significant enlargement of the alveolar air spaces was observed in lung samples from PPEtreated mice compared with control. The means and SD values of the alveolar diameters $(n=117)$, alveolar area $(n=117)$, alveolar wall thickness $(n=77)$, and tissue fraction ratio $(n=$ 20) are summarized in Table 2. The alveolar diameters and areas in the PPE-treated group were significantly larger than in the control group. The SD values of alveolar diameters and alveolar areas in PPE-treated lungs were also statistically significantly larger than those in control lungs, indicating the presence of increased heterogeneity of the alveolar sizes at the microscopic level. However, both the mean and the SD of tissue fraction ratios were significantly smaller in the PPEtreated group. There was no significant difference between the means and SD values of alveolar thicknesses.

\section{DISCUSSION}

The main results of the present study are that 1 ) we developed a novel model to account for the heterogeneities of the lung tissue elastance; 2) the model is able to extract reasonable estimates of the heterogeneities of tissue elastance from simulated data by using a realistic tree model of the mouse lung; 3) application of the model to the respiratory impedance of mice suggests that the distribution of tissue elastance in the emphysematous mouse is wider with a lower minimum and maximum value than that in the normal mouse; and 4) histological analysis of the alveolar structure revealed that the alveolar diameters and their variability were larger, whereas tissue fraction was smaller, in the emphysematous lungs compared with controls.

\section{Model Assumptions}

We tested whether our model was able to extract information about the heterogeneity of lung tissue by fitting the model to respiratory impedance from mice with or without PPE treatment. The primary assumptions made in the model are that 1 ) the model is linear; 2) airway heterogeneity is negligible, i.e., Raw assumed the same value in each pathway in Fig. 1; 3) within any region of the lung, tissue resistance scales with tissue elastance, which means that hysteretic properties of the lung are homogeneous, i.e., $\eta$ was the same in each pathway; and 4) airway wall compliance was negligible.

With regard to nonlinearity, we note that there are several forms of nonlinear mechanisms that can possibly affect the
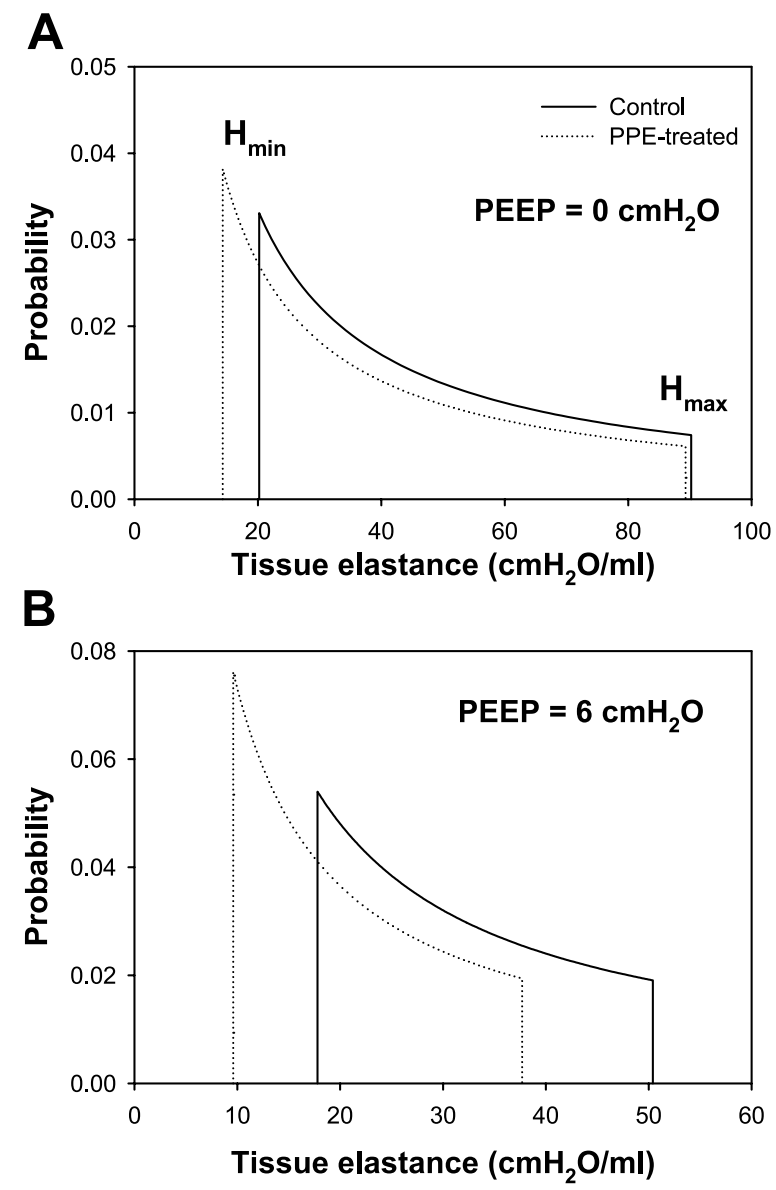

Fig. 4. Representative examples of the hyperbolic distribution of tissue $\mathrm{H}$ in control (solid line) and PPE-treated (dotted line) mice at PEEP levels of $0(A)$ and $6 \mathrm{cmH}_{2} \mathrm{O}(B) . \mathrm{H}_{\min }$, minimum $\mathrm{H} ; \mathrm{H}_{\max }$, maximum $\mathrm{H}$. 


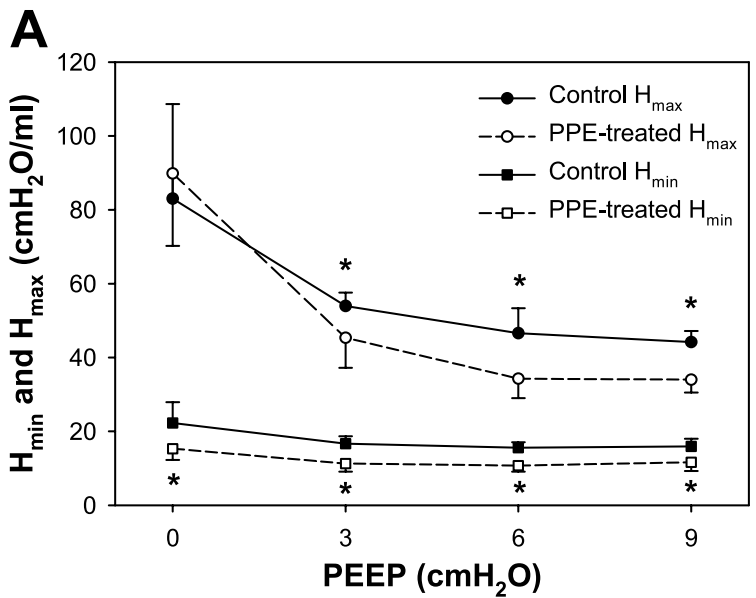

B

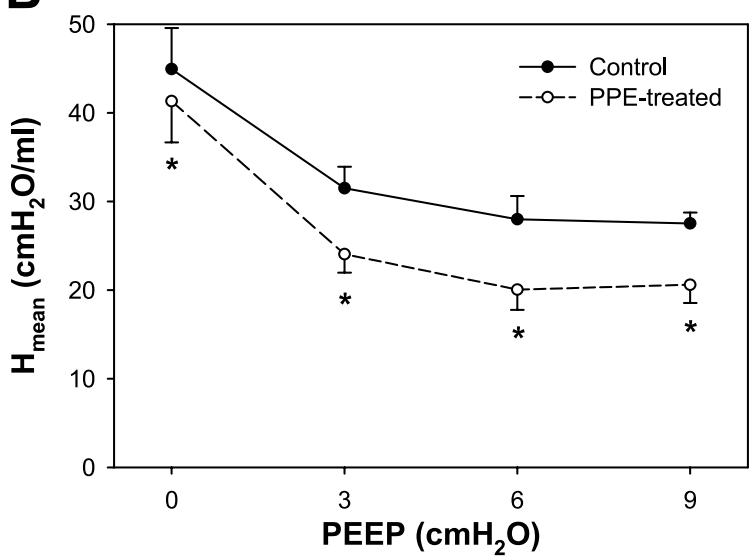

Fig. 5. Means \pm SD of $\mathrm{H}$ parameters $\mathrm{H}_{\min }$ and $\mathrm{H}_{\max }(A)$ and mean $\mathrm{H}\left(\mathrm{H}_{\text {mean }}\right.$; $B$ ) in control $(\bullet)$ and PPE-treated (O) mice as a function of PEEP. $* P<0.05$.

impedance data, including dynamic tissue nonlinearities (29, 39 ), flow nonlinearities $(4,10)$, or nonlinearities associated with flow limitation (30). Because we used the so-called NSND input frequencies, nonlinearities associated with tissues and flow (i.e., Rohrer effect) are not likely to have influenced our data (39). The NSND is a composite waveform, including specially selected sinusoids, which minimizes the effects of harmonic distortion and cross talk at the input frequencies and provides a smooth estimate of the impedance, even when the

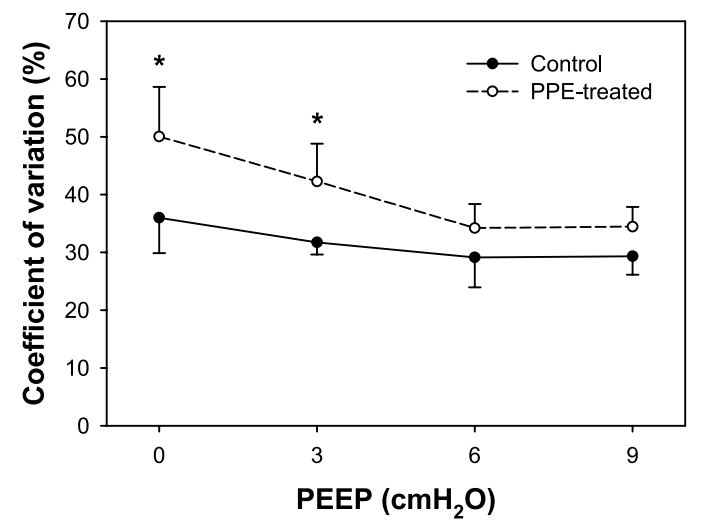

Fig. 6. Means $\pm \mathrm{SD}$ of the coefficient of variation of $\mathrm{H}$ distribution in control $(\bullet)$ and PPE-treated $(O)$ mice as a function of PEEP. $* P<0.05$.
A

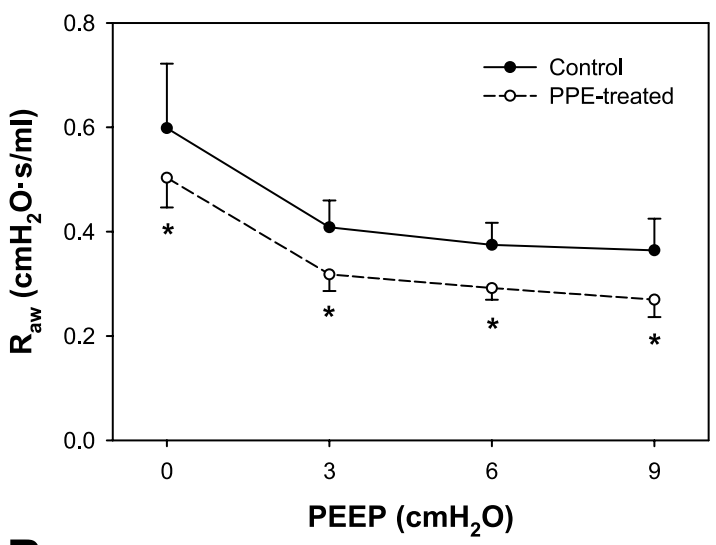

B

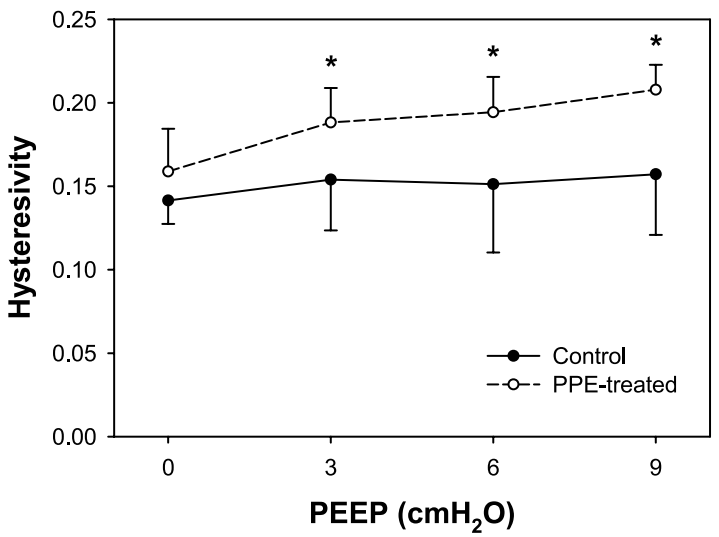

Fig. 7. Means \pm SD of Raw $(A)$ and $\eta(B)$ in control $(\bullet)$ and PPE-treated $(O)$ mice as a function of PEEP. $* P<0.05$.

amplitude of the signal is similar to that of a Vт. We examined the pressure recordings in the time domain and found no traces of flow limitation, even in the emphysematous mice.

We cannot exclude the possibility that airway heterogeneities contributed to the data in the treated animals. However, we note that, in the emphysematous lung, tissue structure and composition are definitely altered $(23,38,43)$, and emphysema is known to cause a large heterogeneity of low-attenuation areas on computed tomography images (3). Our computer model incorporates heterogeneity of lung tissue elastance. The model already fits the data well, and additional mechanisms built into it are not likely to further improve the fit. More importantly, from the measured impedance data, one cannot expect to reliably estimate additional independent parameters. We also note that, strictly speaking, the estimated Raw may have a small contribution from the chest wall. However, because a sharp serial distinction between airways and tissues is difficult, the contribution of airway heterogeneities cannot be completely neglected. To test the contribution of the airway heterogeneity, we also investigated respiratory mechanics of both normal and PPE-treated mice using the heterogeneous airway model introduced by Suki et al. (40). This model fits the impedance data in both groups equally well as the present model. The heterogeneity of Raw, characterized by the CV of Raw (35), depended on PEEP $(P<0.001)$ and was largest at $\mathrm{PEEP}=0$. However, the $\mathrm{CV}$ values of Raw were not different between the control and the PPE-treated mice at any PEEP 

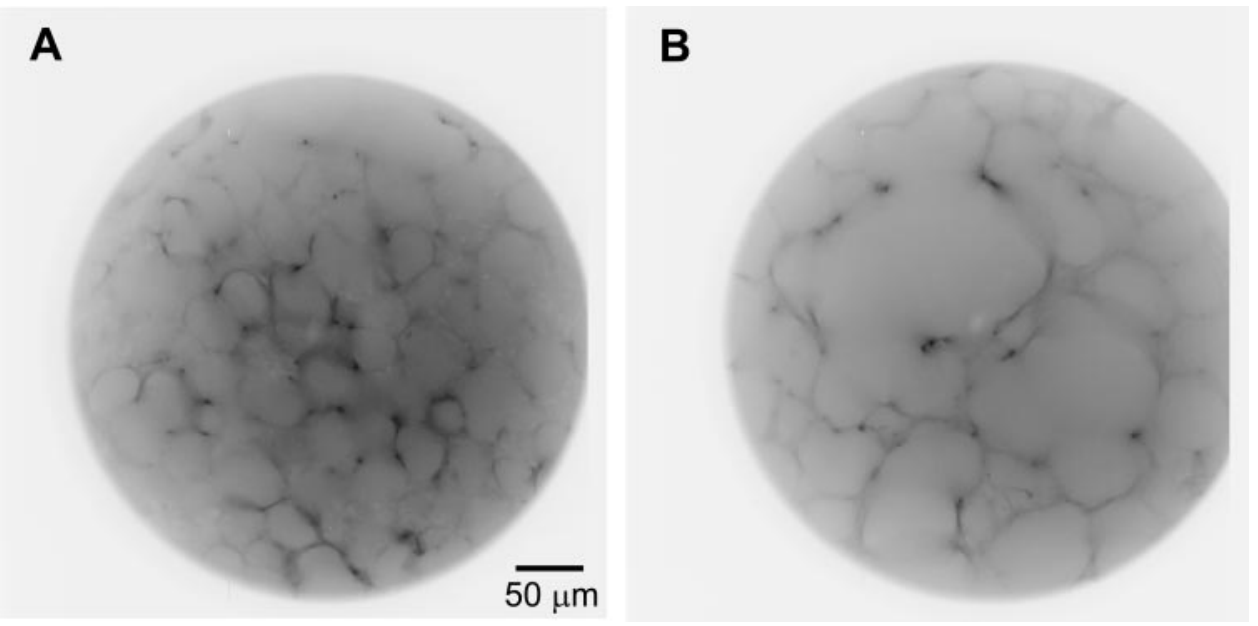

Fig. 8. Examples of alveolar structure of lung tissues from control $(A)$ and PPEtreated $(B)$ mice with the use of a fluorescent microscope.

$(P=0.39$, data not shown). Therefore, although the heterogeneity of Raw may contribute to the respiratory mechanics of mice as in rats (35), the present model clearly shows an increased heterogeneity of $\mathrm{H}$ in the present mouse model of emphysema, which also appears to correlate with heterogeneity of structure (see below).

There are no data in the literature concerning whether regional tissue resistance scales with regional tissue elastance in the normal or emphysematous lung. It is likely that, in emphysema, heterogeneity of structure reaches the single-fiber level due to active remodeling of the connective tissue (43). It is also plausible to assume that, during remodeling, $\eta$ and stiffness can decouple from each other. Indeed, following in vitro digestion of elastin or collagen, $\eta$ of the tissue strip does not always change in the same direction as $\mathrm{H}$ (44). Thus the assumption of a constant $\eta$ is a limitation of the modeling approach that, however, was necessary to obtain closed-form solution for the input impedance.

Finally, it is known that, in emphysema, airway wall properties also change $(10,19)$. Airway wall compliance contributes noticeably to the input impedance only if the peripheral impedance of the lung significantly increases with respect to airway wall impedance (27). However, in our emphysema mice, the model fitting resulted in a decrease of $\mathrm{H}_{\text {mean }}$ and hence a decrease in peripheral lung impedance. Thus it is unlikely that airway wall compliance contributed significantly to our data. This is also supported by the fact that the model was able to extract reasonable estimates of the distribution of $\mathrm{H}$ from the simulated data, even in the presence of compliant airway wall (see Table 1). Additionally, as mentioned above, it does not seem possible to extract more independent parameters from the fitting procedure. Thus we conclude that, even though the parameters of the present model may have been affected to some extent by mechanisms not included in the model, such as nonlinearity, airway heterogeneities, or airway wall compliance, the estimated increased CV of tissue elastance in the treated animals likely reflects true development of structural heterogeneities at the level of the parenchyma.

\section{Time-constant Heterogeneities and Alveolar Structure}

The primary purpose of this study was to develop a model that incorporates a time-constant distribution in a simple manner associated with a distribution of regional tissue elastances and to estimate its presence and magnitude from impedance data of normal and emphysematous mice. We chose pulmonary emphysema as a test model because it is characterized by destruction of the respiratory bronchioles, alveolar ducts, and alveolar walls, which lead to hyperexpansion and loss of elastic recoil (37), and is recognized as a heterogeneous lung disease (34).

Before interpreting the increased heterogeneities obtained by the present model, one may ask the question whether our model with a hyperbolic distribution of tissue elastances fits the data better than the homogeneous model introduced by Hantos et al. (17). We, therefore, compared, on an individual basis, the fitting errors obtained from our model and the single-compartment model of Hantos et al. (17) using $F$-tests. The difference between the errors of the two models was not statistically significant at any PEEP level in the control mice or in the PPE-treated mice (data not shown). This is likely due to the small number (five) of frequencies applied in the OVW tech-

Table 2. Comparison of lung morphometry in PPE-treated and control mice

\begin{tabular}{lcrr}
\hline \hline & & & \multicolumn{2}{c}{ Significance } \\
\cline { 3 - 4 } & Control & PPE Treated & Mean \\
\hline Alveolar diameter, $\mu \mathrm{m}$ & $33.3 \pm 11.9(36)$ & $53.4 \pm 21.9(41)$ & $P<0.001$ \\
Alveolar area, $\mu \mathrm{m}^{2}$ & $1,680 \pm 1,258(75)$ & $4,479 \pm 3,966(89)$ & $P<0.001$ \\
Wall thickness, $\mu \mathrm{m}$ & $4.70 \pm 2.43(53)$ & $5.34 \pm 2.47(46)$ & NS \\
Tissue fraction ratio, $\%$ & $15.0 \pm 5.7(38)$ & $10.5 \pm 3.2(31)$ & $P<0.01$ \\
& & & \\
\end{tabular}

Values are means $\pm \mathrm{SD}$, with coefficient of variation of each parameter, expressed as percent, in parentheses. Differences in means and SD are compared by $t$-test and $F$-test, respectively. NS, not significant. 
nique. The new model reduces the error by $5-30 \%$, but this is insufficient to achieve a statistically significant decrease because the number of parameters (four in the homogeneous model and five in the present model) is about the same as the number of frequencies. However, the new model decreased the error in every single case. Consequently, as shown in Fig. 2, when the fitting errors between two models were compared by using two-way repeated ANOVA, the difference was highly significant in PPE-treated mice $(P<0.001)$. In future studies, it is desirable to increase the number of frequencies, which should also improve the reliability of the parameters. Nevertheless, the results suggest that heterogeneity of tissue elastance does affect organ level dynamic respiratory mechanics and that the present model has the advantage of characterizing this heterogeneity in emphysema. We also note that the PPE treatment of the mice in this study caused only a mild form of emphysema, and we did not expect to find an extreme change in heterogeneity compared with control.

With regard to the interpretation of tissue heterogeneities, we note that the increase in the CV of tissue elastance in the emphysema mice is a consequence of a larger decrease in $\mathrm{H}_{\text {min }}$ than in $\mathrm{H}_{\max }$ (Figs. 5 and 6). In this PPE-induced mild emphysema model, the lungs contain both emphysematous and normal lesions (Fig. 8), and the elastance values of the emphysematous lesions should be less than those of the normal lesions, which is likely due to the loss and remodeling of elastic fibers (43). Therefore, the lowest tissue elastance (model-based $\mathrm{H}_{\min }$ ) values in PPE-treated mice may reflect the physiological function of the emphysematous lesions. It is also possible that the effects of the chest wall and the pleura play a role in determining $\mathrm{H}_{\max }$. To test the possible contribution of the chest wall, we measured respiratory mechanics in four additional normal mice, both in the closed and open chest conditions. We found that the parameters $\mathrm{H}_{\min }, \mathrm{H}_{\max }, \mathrm{H}_{\text {mean }}$, and $\mathrm{CV}$ of $\mathrm{H}$ were all unaffected by the chest wall (Ito $\mathrm{S}$ and Suki B, unpublished observation). Therefore, the contribution of the chest wall to dynamic respiratory mechanics is relatively small in mice. Although the OVW applies a large-amplitude oscillatory signal to mimic tidal breathing, these results are consistent with a previous report that used small-amplitude oscillations in mice (36). Thus we speculate that the statistically significant decrease in $\mathrm{H}_{\max }$ at the higher PEEP levels may be a consequence of the weakened collagen fibers due to the remodeling process itself associated with the PPE treatment (22) or mechanical failure of the remodeled tissue (21).

As shown in Fig. 6, the heterogeneity in the tissue elastance was the largest at the PEEP level of 0 in emphysema mice, and the application of PEEP reduced this heterogeneity. The reason for this reduction may be that, in the supine mouse at zero PEEP, some airways and/or alveoli in the dependent region of the lung collapse, inducing an additional level of heterogeneity. With increasing PEEP, the lung undergoes recruitment, and the associated heterogeneity gradually disappears. Whereas this may be the case in the emphysema mice, the heterogeneity in normal mice was nearly independent of PEEP. Thus the heterogeneity that we observed in the normal mice may reflect baseline heterogeneity of the alveolar structure and probably not compartmental heterogeneity of the chest wall system as in rats (35), because, as shown above, the chest wall did not contribute significantly to our data. Because recruitment and derecruitment of lung units during ventilation is a form of nonlinearity, such nonlinearity may affect respiratory mechanics in the partially collapsed lung at low-PEEP levels. However, it is difficult to pull out this mechanism from impedance data.

The values of $\mathrm{CV}$ calculated from the estimated tissue elastance distribution were utilized as an index of model-based prediction of the tissue heterogeneities. The data suggest that $\mathrm{CV}$ was larger in the emphysematous than in the control mice (Fig. 6). From microscopic images of the alveolar structure (Fig. 8), we also found that the lungs of PPE-induced emphysema mice exhibited larger SD and CV values of alveolar diameters and alveolar area, signs of increased heterogeneities of alveolar sizes. The increase in alveolar size and no change in wall thickness in turn resulted in a decreased tissue fraction in the treated mice. These observations are consistent with a previous report in human patients (9). Because the values of the $\mathrm{CV}$ of the distribution of $\mathrm{H}$ and of the alveolar diameters were similar, both in the normal and emphysematous mice, we speculate that the time-constant inequalities reflected in the frequency dependence of lung impedance may be a consequence of the heterogeneous alveolar structure having a wide distribution of elastance values. Nevertheless, we acknowledge that presently there is no direct correspondence between our model parameters and heterogeneity of structure.

In summary, we have developed a new model that features lung tissue elastance heterogeneities. We also characterized the dynamic respiratory mechanics in a mouse model of emphysema with inhaled PPE treatment and speculated that heterogeneities of the tissue elastance can reflect the underlying heterogeneities of the alveolar structure. Future studies should further explore the structural basis of such tissue elastance heterogeneity obtained from organ level measurements.

\section{GRANTS}

This article is funded by National Heart, Lung, and Blood Institute Grant HL-59215-04.

\section{REFERENCES}

1. Adamicza A, Petak F, Asztalos T, and Hantos Z. Effects of endothelin-1 on airway and parenchymal mechanics in guinea-pig. Eur Respir $J$ 13: 767-774, 1999.

2. Al-Jamal R and Ludwig MS. Changes in proteoglycans and lung tissue mechanics during excessive mechanical ventilation in rats. Am J Physiol Lung Cell Mol Physiol 281: L1078-L1087, 2001.

3. Baldi S, Miniati M, Bellina CR, Battolla L, Catapano G, Begliomini E, Glustini D, and Gluntini C. Relationship between extent of pulmonary emphysema by high-resolution computed tomography and lung elastic recoil in patients with chronic obstructive pulmonary disease. Am J Respir Crit Care Med 164: 585-589, 2001.

4. Barnas GM, Campbell DN, Mackenzie CF, Mendham JE, Fahy BG, Runcie CJ, and Mendham GE. Lung, chest wall, and total respiratory system resistances and elastances in the normal range of breathing. Am Rev Respir Dis 145: 110-113, 1992.

5. Bates JHT, Lauzon AM, Dechmann GS, Maksym GN, and Shuessler TF. Temporal dynamics of pulmonary response to intravenous histamine in dogs: effect of dose and lung volume. J Appl Physiol 76: 616-626, 1994.

6. Collins RA, Ikegami M, Korfhagen TR, Whitsett JA, and Sly PD. In vivo measurements of changes in respiratory mechanics with age in mice deficient in surfactant protein D. Pediatr Res 53: 463-467, 2003.

7. Csendes T. Nonlinear parameter estimation by global optimization: efficiency and reliability. Acta Cybernetica 8: 361-370, 1988.

8. Dolhnikoff M, Mauad T, and Ludwig MS. Extracellular matrix and oscillatory mechanics of rat lung parenchyma in bleomycin-induced fibrosis. Am J Respir Crit Care Med 160: 1750-1757, 1999. 
9. Dunnill MS. Quantitative methods in the study of pulmonary pathology. Thorax 17: 320-328, 1962.

10. Farre R, Peslin R, Rotger M, Barbera JA, and Navajas D. Forced oscillation total respiratory resistance and spontaneous breathing lung resistance in COPD patients. Eur Respir J 14: 172-178, 1999.

11. Fredberg JJ and Stamenovic D. On the imperfect elasticity of lung tissue. J Appl Physiol 67: 2408-2419, 1989.

12. Gattinoni L, Pelosi P, Rossi N, Virtuani L, Brazzi L, and Valenza F. Effects of positive end expiratory pressure on regional distribution of tidal volume and recruitment in adult respiratory distress syndrome and in normal anesthetized subjects. Am J Respir Crit Care Med 151: 1807-1814, 1995.

13. Gomes RFM, Shen X, Ramchandani R, Tepper RS, and Bates JH. Comparative respiratory system mechanics in rodents. J Appl Physiol 89: 908-916, 2000.

14. Gomes RF and Bates JH. Geometric determinants of airway resistance in two isomorphic rodent species. Respir Physiol Neurobiol 130: 317-325, 2002.

15. Gregory TJ, Longmore WJ, Moxley MA, Whitsett JA, Reed CR, Fowler 3rd AA, Hudson LD, Maunder RJ, Crim C, and Hyers TM. Surfactant chemical composition and biophysical activity in acute respiratory distress syndrome. J Clin Invest 88: 1976-1981, 1991.

16. Hantos Z, Adamicza A, Govaerts E, and Daroczy B. Mechanical impedances of lungs and chest wall in the cat. J Appl Physiol 73: 427-433, 1992.

17. Hantos Z, Daroczy B, Suki B, Nagy S, and Fredberg JJ. Input impedance and peripheral inhomogeneity of dog lungs. J Appl Physiol 72: $168-178,1992$.

18. Hubmayr RD. Perspective on lung injury and recruitment: a skeptical look at the opening and collapse story. Am J Respir Crit Care Med 165: 1647-1653, 2002.

19. Ingenito EP, Reilly JJ, Mentzer SJ, Swanson SJ, Vin R, Keuhn H, Berger RL, and Hoffman A. Bronchoscopic volume reduction: a safe and effective alternative to surgical therapy for emphysema. Am J Respir Crit Care Med 164: 295-301, 2001.

20. Kitaoka $\mathbf{H}$ and Suki B. Branching design of the bronchial tree based on a diameter-flow relationship. J Appl Physiol 82: 968-976, 1997.

21. Kononov S, Brewer K, Sakai H, Cavalcante FSA, Sabayanagam C, Ingenito EP, and Suki B. Roles of mechanical forces and collagen failure in the development of elastase-induced emphysema. Am J Respir Crit Care Med 164: 1920-1926, 2001.

22. Lucey EC, Goldstein RH, Stone PJ, and Snider GL. Remodeling of alveolar walls after elastase treatment of hamsters. Results of elastin and collagen mRNA in situ hybridization. Am J Respir Crit Care Med 158: 555-564, 1998.

23. Lucey EC, Kean J, Kuang P, Snider GL, and Goldstein RH. Severity of elastase-induced emphysema is decreased in tumor necrosis factor- $\alpha$ and interleukin-1 $\beta$ receptor deficient mice. Lab Invest 82: 79-85, 2002.

24. Lutchen KR, Hantos Z, Petak F, Adamicza A, and Suki B. Airway inhomogeneities contribute to apparent lung tissue mechanics during constriction. J Appl Physiol 80: 1841-1849, 1996.

25. Lutchen KR, Suki B, Zhang Q, Petak F, Daroczy B, and Hantos Z. Airway and tissue mechanics during physiological breathing and bronchoconstriction in dogs. J Appl Physiol 77: 373-385, 1994.
26. Lutchen KR, Yang K, Kaczka DW, and Suki B. Optimal ventilator waveform for estimating low-frequency respirator impedance in healthy and diseased subjecs. J Appl Physiol 75: 478-488, 1993.

27. Mead J. Contribution of compliance of airways to frequency dependent behavior of the lungs. J Appl Physiol 26: 670-673, 1969.

28. Michaelson ED, Grassman ED, and Peters WR. Pulmonary mechanics by spectral analysis of forced random noise. J Clin Invest 56: 1210-1230, 1975.

29. Navajas D, Maksym GN, and Bates JHT. Dynamic viscoelastic nonlinearity of lung parenchymal tissue. J Appl Physiol 79: 348-356, 1995.

30. Peslin R, Farre R, Rotger M, and Navajas D. Effect of expiratory flow limitation on respiratory mechanical impedance: a model study. $J$ Appl Physiol 81: 2399-2406, 1996.

31. Petak F, Hantos Z, Adamicza A, Asztalos T, and Sly PD. Methacholine-induced bronchoconstriction in rats: effects of intravenous vs. aerosol delivery. J Appl Physiol 82: 1479-1487, 1997.

32. Petak F, Hantos Z, Adamicza A, and Daroczy B. Partitioning of pulmonary impedance: modeling vs. alveolar capsule approach. J Appl Physiol 75: 513-521, 1993.

33. Rocco PRM, Negri EM, Kurtz PM, Vasconcellos FP, Silva GH, Capelozzi VL, Romero PV, and Zin WA. Lung tissue mechanics and extracellular matrix remodeling in acute lung injury. Am J Respir Crit Care Med 164: 1067-1071, 2001.

34. Russi EW, Bloch KE, and Weder W. Functional and morphological heterogeneity of emphysema and its implication for selection of patients for lung volume reduction surgery. Eur Respir J 14: 230-236, 1999.

35. Sakai H, Ingenito EP, Mora R, Abbay S, Cavalcante FSA, Lutchen KR, and Suki B. Hysteresivity of the lung and tissue strip in the normal rat: effects of heterogeneities. J Appl Physiol 91: 737-747, 2001.

36. Sly PD, Collins RA, Thamrin C, Turner DJ, and Hantos Z. Volume dependence of airway and tissue impedances in mice. $J$ Appl Physiol 94: 1460-1466, 2003.

37. Snider GL, Kleinerman J, Thurlbeck WM, and Bengali ZH. The definition of emphysema: report of the National Heart, Lung, and Blood Institute, Division of Lung Diseases Workshop. Am Rev Respir Dis 132: $182-185,1985$.

38. Snider GL, Lucy EC, and Stone PJ. Animal models of emphysema. Am Rev Respir Dis 133: 149-169, 1986.

39. Suki B and Lutchen KR. Pseudorandom signals to estimate apparent transfer and coherence functions of nonlinear systems: applications to respiratory mechanics. IEEE Trans Biomed Eng 39: 1142-1151, 1992.

40. Suki B, Yuan H, Zhang Q, and Lutchen KR. Partitioning of lung tissue response and inhomogeneous airway constriction at the airway opening. J Appl Physiol 82: 1349-1359, 1997.

41. Tanaka R, Al-Jamal R, and Ludwig MS. Maturational changes in extracellular matrix and lung tissue mechanics. J Appl Physiol 91: 23142321, 2001.

42. Tgavalekos NT, Venegas JG, Suki B, and Lutchen KR. Relation between structure, function, and imaging in a three-dimensional model of the lung. Ann Biomed Eng 31: 363-373, 2003.

43. Vlahovic G, Russel ML, Mercer RR, and Crapo JD. Cellular and connective tissue changes in alveolar septal walls in emphysema. Am J Respir Crit Care Med 160: 2086-2092, 1999.

44. Yuan H, Kononov S, Cavalcante FSA, Lutchen KR, Ingenito EP, and Suki B. Effects of collagense and elastase on the mechanical properties of lung tissue strips. J Appl Physiol 89: 3-14, 2000. 